\title{
Evaluation of Reliability Index and Probability of Failure for The Improvement of The Nigerian Empirical Mechanistic Flexible Pavement Analysis and Design System (Nempads)
}

\author{
M. M. Musa ${ }^{1, *}$, A.T. Olowosulu², A. A. Murana ${ }^{3}$, J.M. Kaura ${ }^{4}$, I. Bello $^{5}$, M. Yusuf ${ }^{6}$ and \\ A. Ahmad $^{7}$
}

1,2,3,4,5,6,7 Department of Civil Engineering, Ahmadu Bello University, Zaria, NIGERIA.

\begin{abstract}
The aim of this work was to evaluate reliability index (RI) with respect to fatigue and rutting within the different seasons peculiar to Nigeria, in order to improve Empirical-Mechanistic flexible pavement design approach, using First Order Reliability Method (FORM). Flexible pavement design involves many uncertainties, variabilities, and approximations regarding the input parameters like material properties, traffic loads. Others include subgrade strength, drainage conditions, construction, compaction procedures and climatic factors such as temperature, rainfall, and snowfall, etc. The combination of the variances associated with input parameters contributes to components and system uncertainty, and this combination of variances can have a significant effect on the predicted performance of the pavement. Reliability in pavement design is introduced to consider these uncertainties. Layers thicknesses, material properties, and Equivalent Standard Axle Load (ESAL) were entered into a multi-layer elastic theory software, ELSYM-5, which in turn were used to calculate strains and stresses for different seasons. The results obtained were entered into Nigerian fitted transfer function distress models to compute allowable ESALS. Miner's hypothesis theory equation was used to calculate the cumulative damage due to stress and strains generated. A Framework was generated for finding individual reliability index (RI), systemic reliability index (SRI), and probability of failure. The findings showed that Season I (Winter) recorded the highest component reliability index for fatigue (5.63 for Normal Distribution). Season II (Summer) recorded the lowest component reliability index ( $\beta$ ) for rutting (5.4 for Normal Distribution). Season III (Spring) recorded the lowest component reliability index for fatigue (1.85 for Normal Distribution)
\end{abstract}

Keywords: Reliability index, Probability of Failure, Empirical Mechanistic, Flexible Pavement Analysis.

\subsection{INTRODUCTION}

Design of flexible pavement for roads is succeeded through empirically deterministic based approach. One of the famous methods, is American Association of State Highway and Transportation Officials [1], which was established using the AASHTO Road Test that took place in Illinois within the period of 1958 and 1960. Any design performed using the basis of empirical method in relation to AASHTO road test is limited to the circumstances of that test. Many pavement segments collapsed before the intended design period while others lived longer than what they are designed for as a result of over or under design respectively [2]. Basically, many empirically based methods stake similar drawback as mentioned above. Unfortunately, up to now in Nigeria, practically we still follow this conservative

*Corresponding author (Tel: +234 (0) 806319 0517)

Email addresses: marmusty111@gmail.com (M.M. Musa), atolowosulu@gmail.com (A.T. Olowosulu), fatinoyi2007@gmail.com (A. A. Murana), jmkaura@abu.edu.ng (J.M. Kaura), belloi1040@gmail.com (I. Bello),ysuidi58@gmail.com (M. Yusuf),

azizdanbaba02@gmail.com (A. Ahmad) method of design despite all the drawbacks.

On the other hand, Empirical-Mechanistic (M-E) tactic is advanced in the sense that, it utilizes basics of mechanical display and performance interpretations in finding the requisite pavement depth for a set of design circumstances. Empirical-Mechanistic (M-E) approach in summary, has the competency of changing and utilizing to new findings in road surface design by depending on mechanics of material [3]. The Empirical-Mechanistic approach utilizes mechanics of materials, that converts inputs such as applied wheel loads to results such as road surfacing reaction [4].

Design of flexible pavement involves many uncertainties, variabilities, and approximations regarding to material properties, traffic loads, subgrade strength, drainage conditions, construction, compaction procedures and climatic factors such as temperature, rainfall, and snowfall [5]. The combination of the variances associated with input variables contributes to components and system uncertainties, and this combination have a significant effect on the predicted performance of the pavement [6]. Reliability in pavement design is introduced to consider these uncertainties. Advantages of using reliability includes the calibration of new design 
methods, developing rational design specifications, optimizing resources, and assessing the damage and remaining life of the pavement [7]. For example, M-E methods can adapt to new design conditions (e.g., heavier loads, new pavement materials) by relying primarily upon mechanistic pavement modelling.

The 1993 AASHTO guide expressed the term 'reliability of a road pavement portion' as the likely hood that a pavement portion will perform satisfactorily throughout its design lifecycle pending on the external forces like traffic and the weather situations" [1]. It is therefore important to consider integrating reliability computational analysis into the design framework of road pavement structures, such that the accuracy of road pavement lifetime estimation will be greatly improved. Reliability applications encompasses gradation of new design approach, evolving balanced design provisions, optimizing resources, and evaluating the damages and residual lifecycle of the road pavement. For instance, ME approach embrace new design situations. First Order Reliability Method (FORM) can be used to simulate and find the effects of the input variables [8] with the help of MATLAB program.

In this paper, the aim is to evaluate the reliability index (RI) with respect to fatigue and rutting within the different seasons peculiar to Nigeria, in order to Improve Empirical- Mechanistic Flexible pavement roads design approach. Previous researchers like, [9], [7] and [3], all worked on similar area where they evaluated the variabilities with respect to pavement materials, environmental factors, traffic loading and finally computed component reliability index, system reliability index and probability of failure.The difference of this research with their own, is computing the reliability index with respect to the seasons peculiar to Nigeria to see the effect of environmental condition in each season.

Transfer function uses road pavement reactions computed by the mechanistic model and envisage the lifecycle of road surface in terms of fatigue cracking or rutting [10]. The best Nigerian situation fitted Fatigue and rutting distress models [11] and [12], are used which became the Pavement lifetime equation. It relates pavement damages and reactions in the road frame structure [13]. The effects of rainfall and temperature on each season is established.

\subsection{MATERIAL AND METHODS \\ 2.1 Material}

(a) Laboratory Test: - 20-soil samples were collected using $200 \mathrm{~mm}$ diamond core barrels, at $0.5 \mathrm{~m}$ depth below the existing ground level, and at interval of $0.5 \mathrm{~km}$ along the Kaduna to Abuja Road Northwest geographical zone, in December 2011.The 10km length portion of the road traverses Doka, Bichini and Jere Villages. The samples were tested to get their respective material properties that includes: - Layer thicknesses, and layers resilient modulus from Pavement Evaluation unit (PEU) Rigachikun, Federal Ministry of Works, Kaduna.

Layer Thicknesses: - From the cored samples, the thicknesses of Asphalt surfacing, subbase and base layers were determined using a measuring ruler.

Resilient Modulus: - In this study, UTM-5 Pservopneumatically controlled testing machine was used to determine resilient modulus of asphaltic surface, base and subbase materials. The resilient modulus values for the asphaltic surface layers were computed in accordance to American Society of Testing Materials (ASTM, 4123).

Haversine-shaped load pulse was set at 0.1 seconds and the rest period was 0.9 seconds. The testing was conducted at the temperature of $35^{\circ} \mathrm{C}$, which is the pavement temperature at one-third depth of the asphaltic concrete layer thickness, based on the room temperature of $27^{\circ} \mathrm{C}$.The samples were later conditioned. The procedure was repeated whereby the maximum test load and Poisson's ratio were set. The resilient modulus (in $\mathrm{MPa}$ ) was determined from equation 1: Total Resilient Modulus,

$$
E R T=\mathrm{P}(v \mathrm{RT}+0.27) / \mathrm{t} \Delta \mathrm{HT}
$$

where: $-\mathrm{P}=$ repeated load $(\mathrm{N}), \mathrm{t}=$ thickness of specimen $(\mathrm{mm}), \nu \mathrm{RT}=$ total resilient Poisson's ratio $\Delta \mathrm{HT}=$ total recoverable horizontal deformation $(\mathrm{mm})$

Resilient Modulus of Base and Subbase material: - To determine the resilient modulus of unbound base and subbase material, I used universal triaxial cell of $100 \mathrm{~mm}$ diameter x 200mm high for repeated load test. For each sample, the optimum moisture content was first found using modified proctor test $(4.5 \mathrm{~kg}$ rammer). The specimens were tested for resilient modulus using the Universal Transverse Mercator (UTM-5P) machine at the deviator stress and confining pressures. we set the repeated load at a duration of 0.1 seconds and the rest period of 0.9 seconds. Resilient modulus tests were then conducted at the confining pressures and deviator stress ( 15 cycles) for 100 repetitions. The average of the last five readings for each cycle was recorded as the resilient modulus for the particular cycle. The data obtained for the 15 cycles were then plotted based on the relationship in equation 2 for the base/subbase materials: -

$$
M_{p}(p s i)=K_{1}(\theta)^{K_{2}}
$$

Where:

$\theta=$ Stress invariant or Bulk stress $(\mathrm{psi})=\left(\sigma_{1}+\sigma_{2}+\sigma_{3}\right)=$ $\left(\sigma_{d}+3 \sigma_{3}\right)$.

$\sigma_{l}=$ Major principal stress (psi).

$\sigma_{2}=$ Intermediate principal stress (psi).

$\sigma_{3}=$ Minor principal stress/confining pressure (psi).

$\sigma_{d}=$ Deviator stress (psi). 
$k 1, k 2=$ Regression constants from repeated load resilient modulus tests.

(b) Traffic Volume Count: - Traffic Volume count was conducted along Kaduna to Abuja Road using an Automatic Traffic Recorder (ATR), and Automatic Vehicles Classifier (AVC) in order to collect vehicle volume by vehicle category. A 24-hour count was conducted for a duration of 7 days. Vehicles were classified under: -Car, bus, 2-axle (4-tire truck), 2-axle (6tire truck),3+axle truck(single), and 5+axle truck(single). These are recorded as average daily traffic (ADT). Passenger car unit (PCU) factors were applied to convert different classes of vehicles to their equivalent passenger car units. A general equation for the accumulated ESAL for each category of axle load is obtained from [14] as: -

$\mathrm{N}($ ESALS $)=$ ADT $x$ Grn $\times$ DDF X LDF $x$ Pt $x$ Favg

Where: - ESALS = equivalent Standard Axle Load $18,000-\mathrm{lb}(80 \mathrm{kN})$ single-axle load for the axle category $\mathrm{iGrn}=$ growth factor for a given growth rate $r$ and design period $\mathrm{n}, \mathrm{ADTi}=$ Average daily traffic for axle category $\mathrm{i}, \mathrm{DDF}=$ Directional Distribution factor $=0.5, \mathrm{LDF}=$ Lane distribution factor $=1, \mathrm{Pt}=$ percentage of trucks

Favg $=$ Average Load equivalence factor

$G r n=\left[(1+r)^{n}-1\right] / r$

Where $i=r / 100$

$\mathrm{i}=$ growth rate, $\mathrm{n}=$ design life, $\mathrm{yrs}=7 \%$ [15].

Table 1 present the data collected in terms of Traffic volume count, Pavement layers material properties. Table-2 presents the seasonal modulus factors [16]. Table3 a presents thickness of the pavement layers of 5- different samples collected earlier, Table-3b present study seasons description with respect to temperature and rainfall [16]. Computed accumulated damage in terms of fatigue and rutting is presented in Table, 4 and 5 respectively using thicknesses in Table-3. The overall system reliability index and probability of failure computed using the thicknesses in Table- 3 is presented in Table-6. Component reliability index $(\beta)$ of each of the four seasons was plotted against the horizontal tensile strain below the Asphalt layer (Et) for fatigue, and compressive tensile strain at the top of the subgrade (Ev) for rutting generated in each season are presented in Figures-2, 3, 4, 5, and 6.

\section{$2.2 \quad$ Method}

Layers thicknesses, poison ratio, resilient modulus, modulus seasonal factors and total ESAL were entered into a multi-layer elastic theory software, ELSYM-5, which in turn were used to calculate the Horizontal tensile strain $\left(E_{t}\right)$ at the bottom of the asphalt surface, and the vertical compressive strain (Ev) at the top of the subgrade for different seasons. The results obtained from ELSYM-5 were entered into fatigue and rutting distress models in order to calculate the allowable number of equivalent single axle (NF) and (NR) in terms of fatigue and rutting respectively. Miner's hypothesis theory equation was used to calculate the cumulative damage due to stress and strains generated. With the aid of MATLAB and using First Order Reliability Method (FORM), a framework was generated for finding individual reliability index (RI), systemic reliability index (SRI), and probability of failure. using Taylor series linearization of limit state funciton $\mathrm{g}(\mathrm{X})$ was carried out and reliability index $(\beta)$ calculated as minimum distance between the origin of random variable space to the failure surface. The following steps were followed to execute FORM: -

i. $\quad$ random variables were determined.

ii. Mean value, $\mu \mathrm{i}$, and standard deviation, $\sigma_{\mathrm{i}}$, of random variables were defined.

iii. The limit state function was formulated using all the appropriate parameters for all the random variables.

iv. The limit state function was expressed in terms of reduced variables.

v. Reliability index $(\beta)$ is the shorted distance between origin and the limit state surface in normalized variable space.

As expressed in equation 5

$$
\beta=\min x \sqrt{\frac{[X i-\mu i]^{T}}{\sigma i} \frac{1}{[\rho]}-\frac{[X i-\mu i]^{1}}{\sigma i}}
$$

Where, $\mathrm{x}_{\mathrm{i}}=$ is one of the uncertain variables in vector $\mathrm{x}$ of input parameters in the reliability analysis,

$\mu_{\mathrm{i}}, \sigma_{\mathrm{i}}=$ are the corresponding mean value and standard deviation of the variable $\mathrm{xi}$,

$[\rho]=$ is the correlation matrix for all the input variables.

Input considered comprises of: calculated allowable number of equivalent single axle (NF) and (NR) in terms of Fatigue and Rutting respectively.The whole process is shown in Figure-1. Four seasons were used in the study, namely:- Winter (starts from 1st week of December to 2nd week of February), Spring (starts from 2nd week of February to 2nd week of May), Summer (starts from 2nd week of May, to 1st week of October), and Autumn (starts from 1st week of October to 1st week of December) period, over which cumulative damage was computed for each period. When the damage index exceeds unity failure follows, of which the thicknesses of the layers is adjusted, or increased. In a situation where by the damage index is far less than one, it signifies the layer is over designed and therefore thickness should be reduced, but when the damage index equal or near one, then the design is satisfactory. 
Table 1: Traffic Volume Count, Soil Samples Average material properties For Abuja to Kaduna Road,2011

\begin{tabular}{cccccc}
\hline Traffic (veh) & \multicolumn{3}{c}{ Modulus (mpa) } & \multicolumn{2}{c}{ Poisson ratio } \\
\hline Average daily traffic & 2,711 & Asphalt surfacing & 4827 & Asphalt surfacing & 0.35 \\
Percent trucks & 27.4 & Base & & & \\
Average load equivalence factor & 3.35 & Sub-base & 551 & Base & 0.40 \\
Directional distribution factor & 0.5 & Sub-grade & 344 & Sub-base & 0.40 \\
Lane distribution factor & 1.0 & & 193 & Sub-grade & 0.45 \\
Annual traffic growth rate & $5 \%$ & & & & \\
\hline
\end{tabular}

Table 2: Modulus seasonal factors

\begin{tabular}{llllll}
\hline S/N & Layers & $\begin{array}{l}\text { Season 1 } \\
\text { (WINTER) }\end{array}$ & $\begin{array}{l}\text { Season II } \\
(\text { SUMMER })\end{array}$ & $\begin{array}{l}\text { Season III } \\
(\text { SPRING })\end{array}$ & $\begin{array}{l}\text { Season IV } \\
(\text { AUTUMN) }\end{array}$ \\
\hline $\mathbf{1}$ & HMA & 4.39 & 2.14 & 0.57 & 1 \\
$\mathbf{2}$ & Base & 4.16 & 0.60 & 0.99 & 1 \\
$\mathbf{3}$ & Subbase & 2.85 & 0.69 & 0.93 & 1 \\
$\mathbf{4}$ & SuB Grade & 5.5 & 0.57 & 0.96 & 1 \\
\hline
\end{tabular}

Source: (Yakubu, 2011)

Table 3a: pavement layers thickness

\begin{tabular}{lllll}
\hline Design & Asphalt Surfacing & Base course & Sub base course & Sub grade \\
\cline { 2 - 5 } alternatives & $\mathrm{mm}$ & $\mathrm{mm}$ & $\mathrm{mm}$ & $\mathrm{mm}$ \\
$\mathbf{1}$ & 100 & 165 & 180 & 7,620 \\
$\mathbf{2}$ & 100 & 200 & 250 & 7,620 \\
$\mathbf{3}$ & 125 & 200 & 250 & 7,620 \\
$\mathbf{4}$ & 125 & 250 & 275 & 7,620 \\
$\mathbf{5}$ & 150 & 250 & 275 & 7,620 \\
\hline
\end{tabular}

\subsection{Transfer Functions}

The empirical component of M-E design is pavement life equation, known as a transfer function (Distress Model). Transfer function uses pavement responses calculated by the mechanistic model and predict the life of pavement in terms of fatigue cracking or rutting. In fact, transfer functions act as a chain between the pavement reactions and appeared damages in the pavements [13].

\subsubsection{Fatigue distress model}

$N_{F}=1.66 \times 10^{-10}\left(E_{t}\right)^{-4.32}[11],[14]$.

Where: $\mathrm{E}_{\mathrm{t}}=$ Horizontal tensile strain below the asphalt layer.

$\mathrm{N}_{\mathrm{F}}$ = Design equivalent single axle with reference to

Fatigue

$\mathrm{n}_{\mathrm{i}}=$ Applied Load, fatigue Failure distress model

equation

$G(x)=1.66 \times 10^{-10}\left(E_{t}\right)^{-4.32}-n_{i}$
$N f-n i=0$

2.3.2 Rutting distress model

$N_{R}=2.56 \times 10^{-8}\left(E_{v}\right)^{-4.5337}[12],[14]$.

Where: $E_{v}=$ the vertical compressive strain on the subgrade

$N_{R}=$ Design equivalent single axle with reference to Rutting

$\mathrm{n}_{\mathrm{i}}=$ Applied Load, Rutting failure distress model equation.

$G(x)=2.56 \times 10^{-8}\left(E_{v}\right)^{-4.5337}-n_{i}$

$N R-n i=0$

Damage, $D i=n i / N i$

\subsection{Safety margin, probability of failure and reliability}

In probabilistic analyses, often a standard normal distribution is assumed for various random variables 
which are then called normal variates. Let $\mathrm{R}$ be the resistance (capacity or strength) of a structure and $\mathrm{S}$ the action (load or load effect) on the structure. The safety margin, $\mathrm{M}$ may be defined as the difference between $\mathrm{R}$ and $\mathrm{S}$ and if it is less than zero, failure can be expected. The safety margin, $\mathrm{M}$, can be written as:

$M=R-S[9]$.

The probability of failure, $\mathrm{p}_{\mathrm{f}}$, is defined as the probability that $(\mathrm{R}-\mathrm{S})$ is less than or equal to zero.

Then, the reliability of the pavement, $\mathrm{Rp}$, is given by,

$$
R p=1-P f
$$

The probability of failure (Pf) can be mathematically expressed as,

$P f=\operatorname{Pr}(g(X) \leq 0)=\int \ldots \int g(X) \leq 0 f X(x) d x \quad[5]$.

Where, $\mathrm{Pf}=$ is the probability of failure,
$\mathrm{g}(\mathrm{X})=$ is the limit state function,

$\mathrm{X}=$ is the random variable,

and $\mathrm{fX}(\mathrm{x})=$ is the density function of variable $\mathrm{X}$.

Reliability can then be calculated using the expression.

$R=1-P f$

Using a FORM approximation, the probability of failure is simply calculated by:

$$
P f=\phi(-\beta)
$$

Where $\beta$ is the Reliability index

\subsection{Study location and period}

The study location was along the Kaduna to Abuja road North West geographical zone, area at $9^{0} 36^{\prime}$ 8 ' $\mathrm{N} 7^{0} 43$ '29' $\mathrm{E}$,.The $10 \mathrm{~km}$ length portion of the road traverses Doka, Bishini and Jere Villages as indicated in figure 1a. The study was conducted in December, 2011.

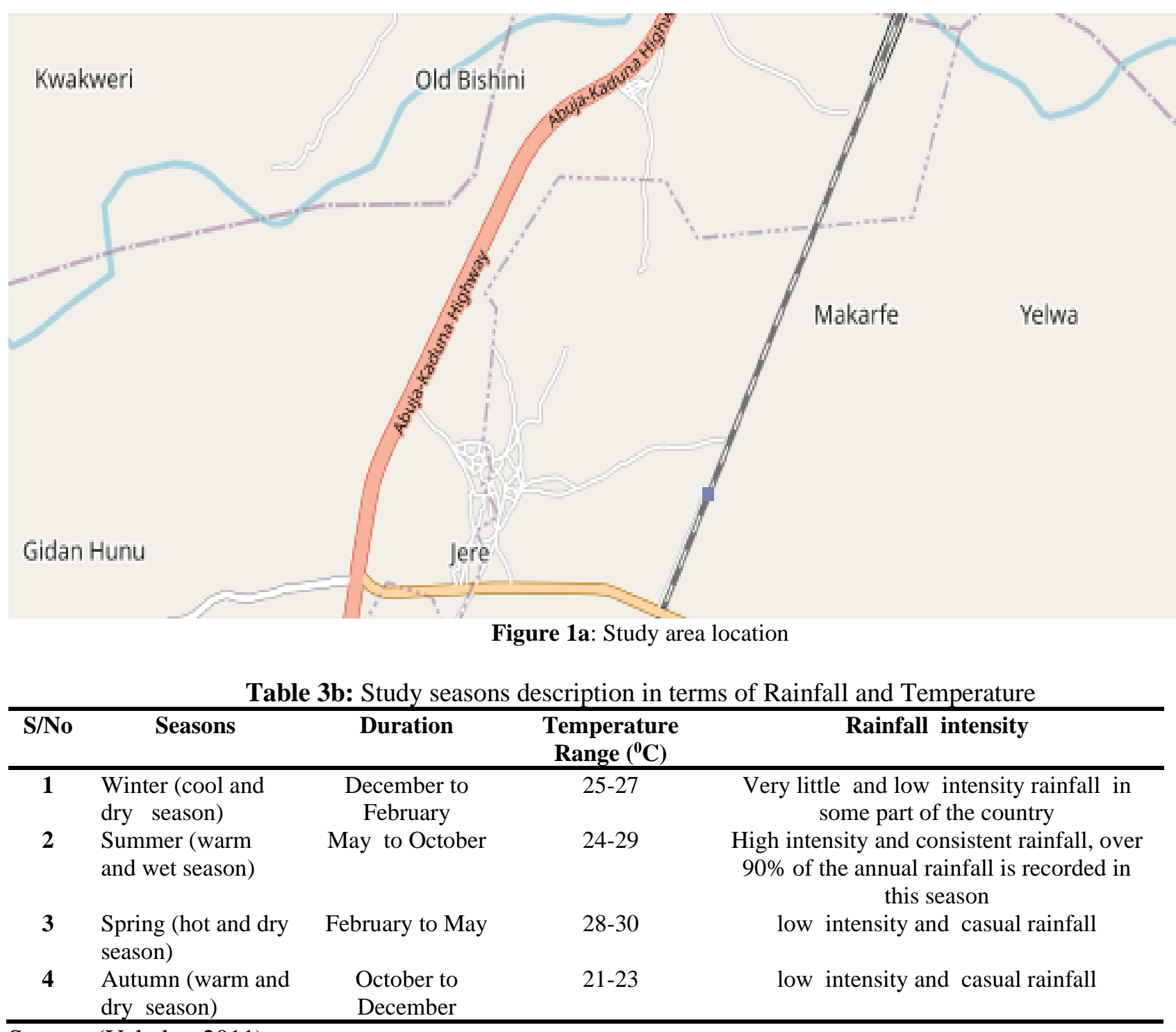

Source: (Yakubu, 2011) 


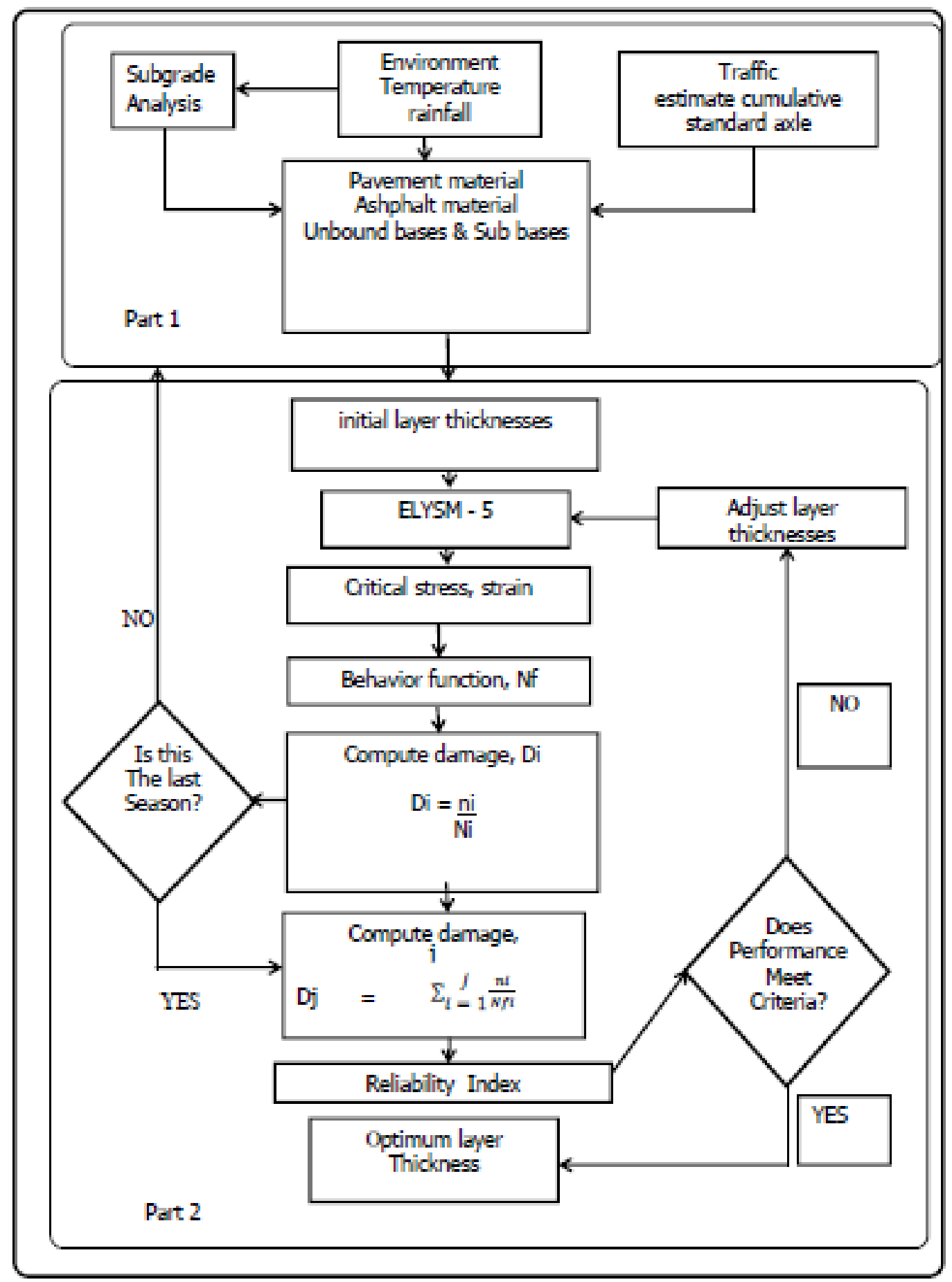

Figure 1b: Reliability Based Empirical - Mechanistic Pavement Design Procedure

\subsection{RESULTS AND DISCUSSIONS}

The reliability studies were carried out with respect to Fatigue and rutting within the different seasons peculiar to Nigeria, in order to Improve EmpiricalMechanistic Flexible pavement design approach. The results are presented in figures $2,3 \mathrm{a}, 3 \mathrm{~b}, 4,5$, tables 4,5 and 6. Figures- 2 to 5 show a relationship between the reliability index $(\beta)$ and horizontal tensile strain below the asphalt layer $\left(E_{t}\right)$ with respect to fatigue, or vertical compressive stain at the top of the $\operatorname{subgrade}\left(\mathrm{E}_{\mathrm{V}}\right)$ with respect to rutting, using coefficient of variation $(\mathrm{COV})$ of $25 \%$ and 3-different probability distribution functions:-
Normal, Lognormal, and Gumbel distribution. Table-4 shows the results of fatigue accumulated damage for all seasons. Table-5 presents rutting accumulated damage for all seasons. While Table 6 exhibits the overall system reliability index and probability of failure between the two failure modes (Fatigue and Rutting), using Coefficient of Variation (COV) of $25 \%$.

$\beta 1$ - is the reliability index when the probability distribution is Normal, $\beta 2$ - is the reliability index when the probability distribution is Lognormal, and $\beta 3$ - is the reliability index when the probability distribution is Gumbe 


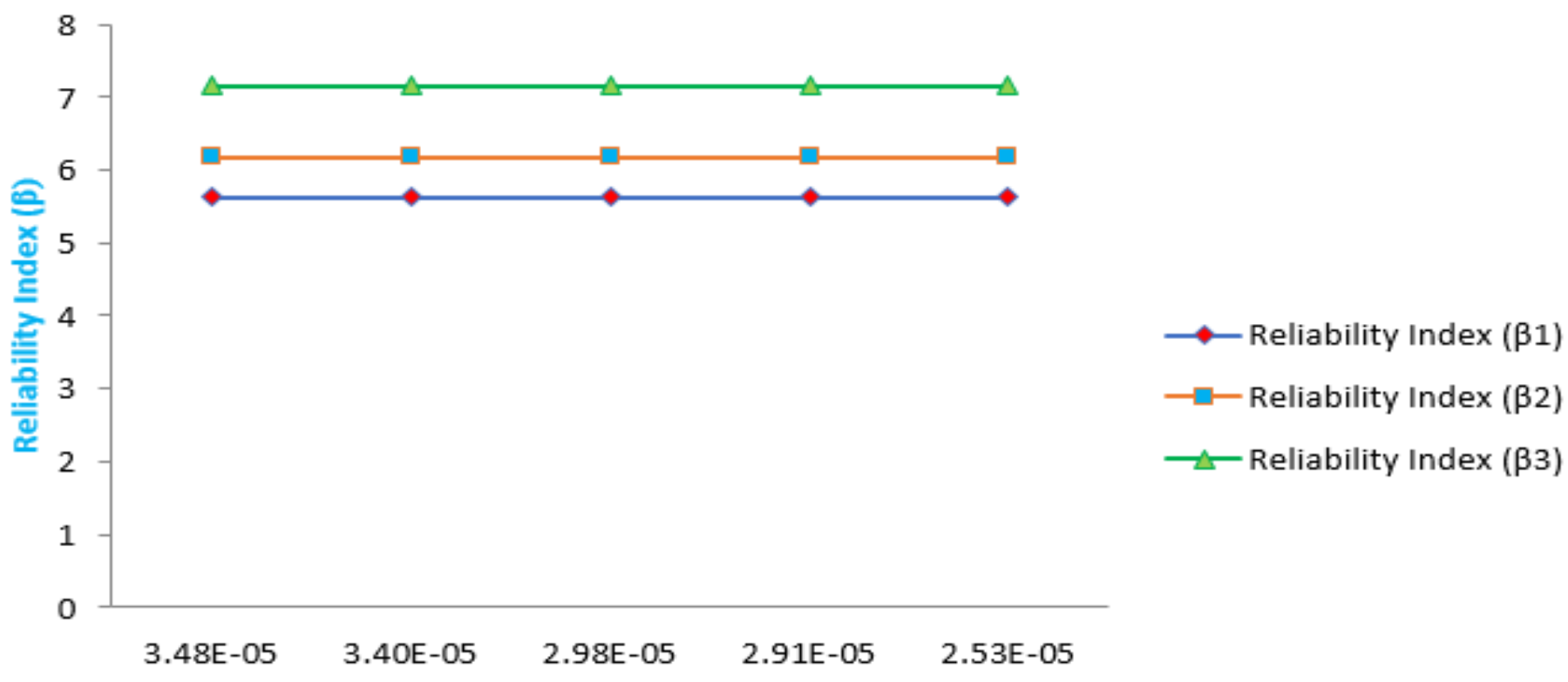

\section{Horizontal tensile strain below the Asphalt Layer $\left(E_{t}\right)$ for fatigue in each trial layers thickness for season 1}

Figure 2: Relationship between Reliability Index ( $\beta$ ) and Horizontal tensile strain (Et), using COV of $25 \%$ for Season-1

Figure-2 shows the relationship between the Reliability Index $(\beta)$ and horizontal tensile strain $\left(E_{t}\right)$, using COV of $25 \%$ for Season-1 (Winter). It is shown that as the value of tensile strain reduces, the reliability index remains relatively constant. This is because the reliability index is not very sensitive to change in fatigue tensile strain under this season and the season favours the resilient modulus strength of asphalt. The effect of choice of probability distribution of random variables was also reflected, where Gumbel produced higher reliability index, followed by Log-Normal, while Normal produced lowest reliability index. It was also found that season-I has recorded the highest component reliability index for fatigue, by implication the season has favourable effect on flexible pavement (roads have longer design life during this season), and this is because of the effect of low temperature on the pavement resilient modulus during the season period that makes it very stiff. This is true with the Fatigue and ruting accumulated damages as shown in Table- 4 and 5 respectively, which are the smallest.

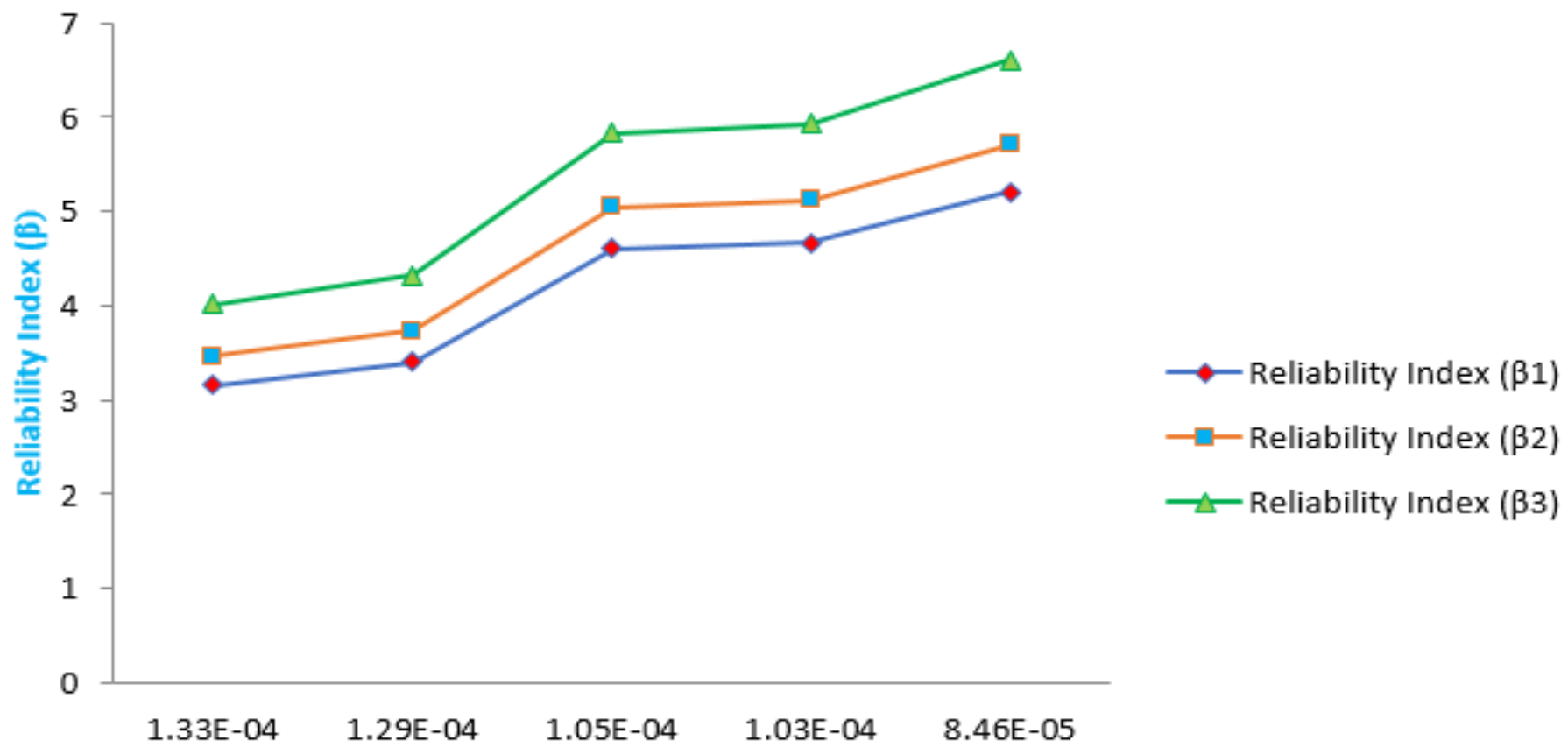

Horizontal tensile Strain below the Asphalt Layer $\left(E_{t}\right)$ for fatigue in each trial layers thickness for season 2

Figure 3a: Relationship between Reliability Index ( $\beta$ ) and Horizontal tensile strain (Et), using COV of $25 \%$ for season-2 


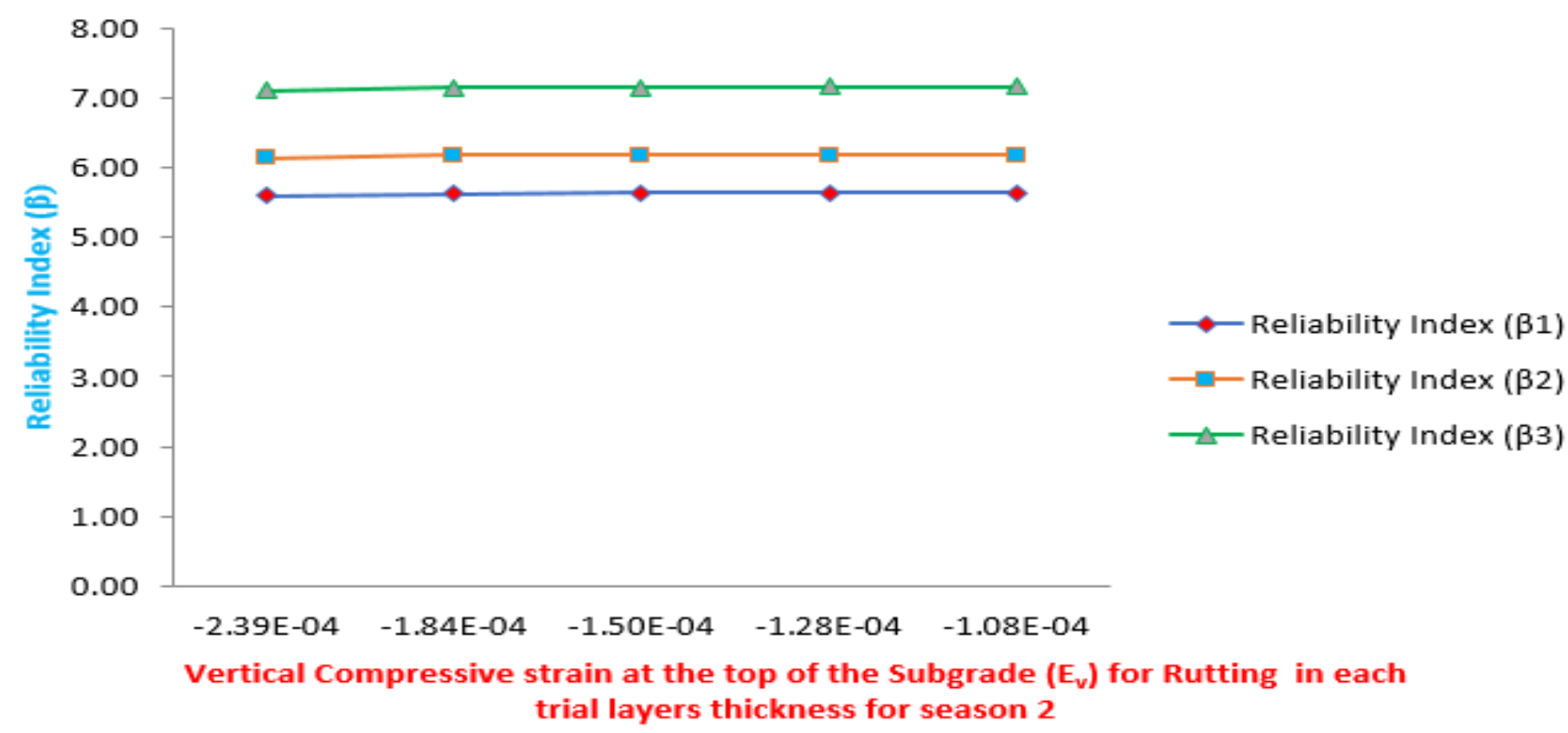

Figure 3b: Relationship between Reliability Index $(\beta)$ and Vertical compressive strain (Ev) For rutting, using COV of $25 \%$ for season-2

Fig-3a shows the relationship between the Reliability Index $(\beta)$ and Horizontal tensile strain (Et), using COV of $25 \%$ for Season-II (Summer) under fatigue. It is shown that as the value of tensile strain reduces, the reliability index increases. This is because the reliability index is sensitive to change in fatigue tensile strain under this season. Fig-3b shows the relationship between the Reliability Index $(\beta)$ and Vertical Compressive strain $\left(\mathrm{E}_{\mathrm{V}}\right.$ ), using COV of $25 \%$ for Season-II (Summer) under rutting. It is shown that as the value of tensile strain reduces, the reliability index remains relatively constant This is because the reliability index is not sensitive to smaller changes in rutting tensile strain under this season.
Also, the effect of choice of probability distribution of random variables was also reflected, where Gumbel produced higher reliability index, followed by LogNormal, while Normal distribution produced lowest reliability index. It was also found that season-II has recorded the lowest component reliability index $(\beta)$ for rutting (Fig-3b), by implication flexible pavement roads are being adversely affected by rutting stresses during this season, which is as a result of the effect of moisture on the pavement subgrade material resilient modulus that makes it very weak. This is true with the rutting accumulated damages as shown in Table- 5 which are the highest.

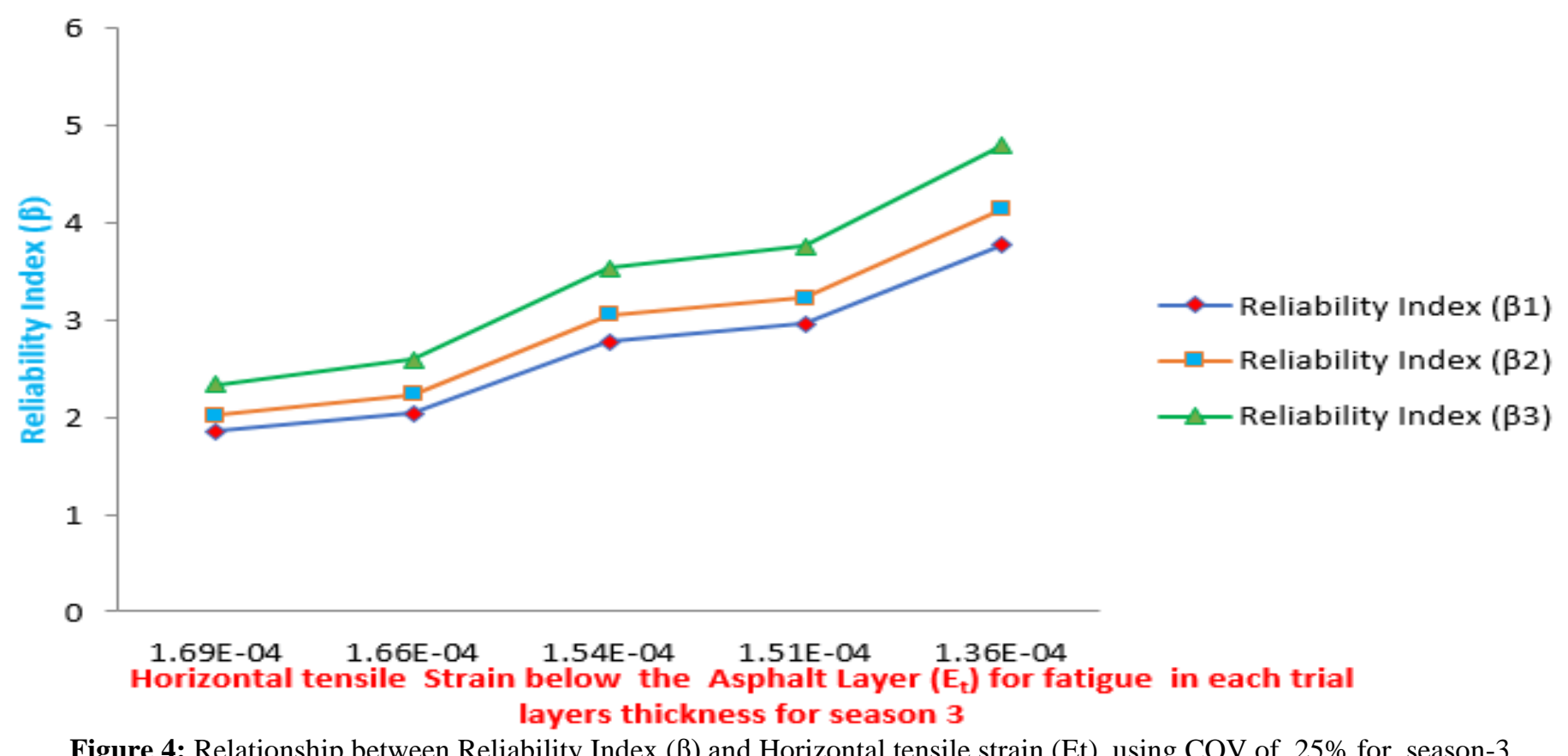

Nigerian Journal of Technology (NIJOTECH)

Vol. 40, No. 4, July, 2021. 
Figure-4 shows the relationship between the Reliability Index $(\beta)$ and Horizontal tensile strain $\left(E_{t}\right)$, using COV of $25 \%$ for Season-III (Spring). It is shown that as the value of tensile strain reduces, the reliability index increases. This is because the reliability index is sensitive to change in tensile strain under this season. Also the effect of choice of probability distribution of random variables was also reflected, where Gumbel produced highest reliability index, followed by Log-Normal, while
Normal produced lowest reliability index. It was also found that season-III has recorded the lowest component reliability index $(\beta)$ for fatigue, by implication flexible pavement are being adversely affected by fatigue stresses during this season, which is as a result of the effect of high temperature on the pavement surface resilient modulus which makes it weak. This is true with the fatigue accumulated damages as shown in Table- 4 which is the highest.

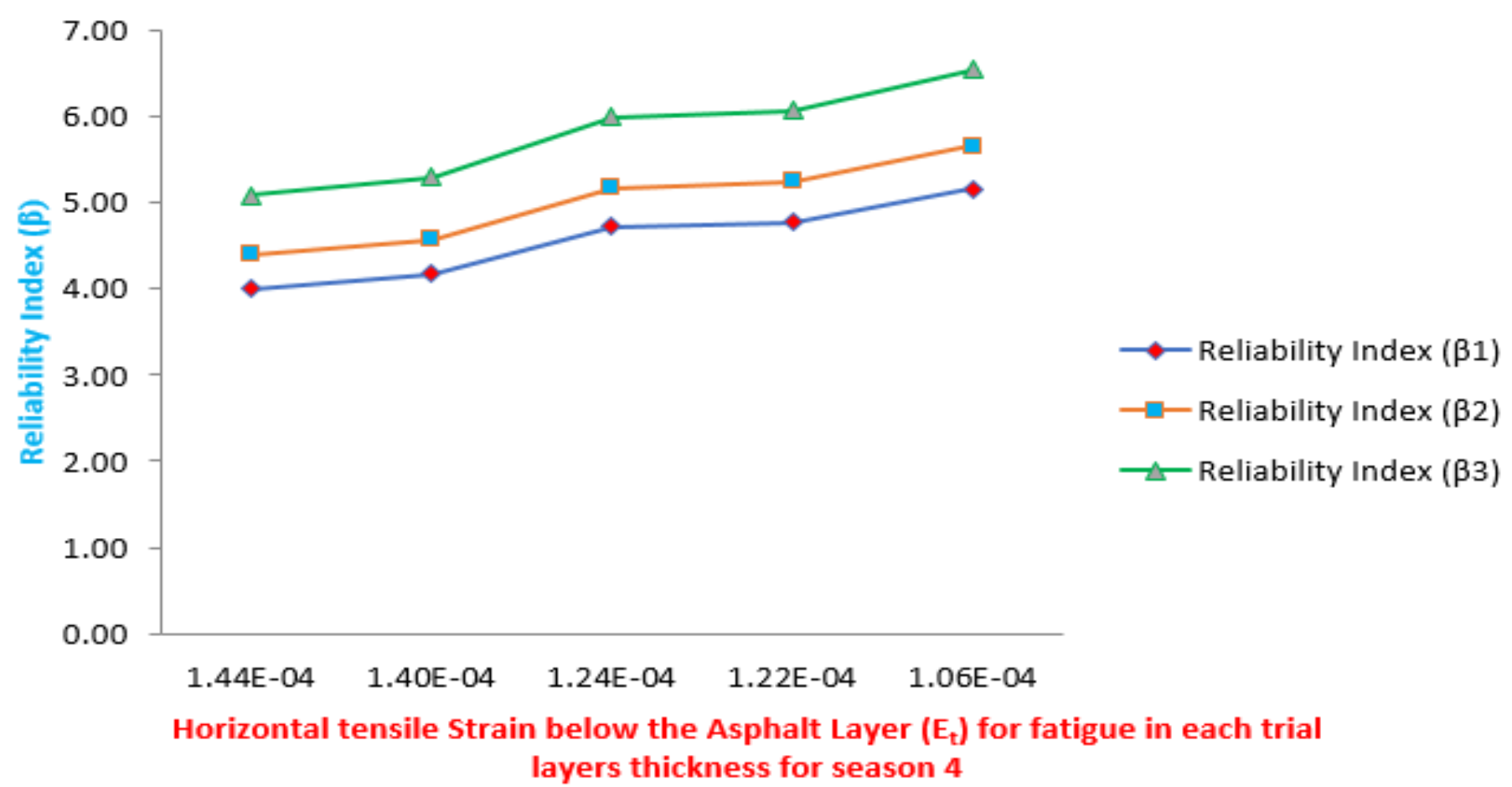

Figure 5: Relationship between Reliability Index $(\beta)$ and Horizontal tensile strain (Et), using COV of $25 \%$ for season 4

Figure-5 shows the relationship between the Reliability Index $(\beta)$ and Horizontal tensile strain $\left(E_{t}\right)$, using COV of $25 \%$ for Season-IV (Autumn). It is shown that as the value of tensile strain reduces, the reliability index increases. This is because the reliability index is sensitive to change in tensile strain under this season Also the effect of choice of probability distribution of random variables was also reflected, where Gumbel produced highest reliability index, followed by Log-Normal, while
Normal produced lowest reliability index. It was also found that season-IV has recorded the moderate component reliability index $(\beta)$ for fatigue, by implication flexible pavement roads are being affected by fatigue stresses during this season, which is as a result of the effect of moderate temperature on the pavement surface resilient modulus which makes it relatively weak. This is true with the fatigue accumulated damages as shown in Table- 4 which are the moderate.

Table 4: Computation of Fatigue accumulated damage for all seasons

\begin{tabular}{lllllll}
\hline \multirow{2}{*}{ Analysis } & \multicolumn{5}{l}{ NO OF TRIALS } \\
\cline { 2 - 7 } & & $\mathbf{1}^{\text {st }}$ & $\mathbf{2}^{\text {nd }}$ & $\mathbf{3}^{\text {rd }}$ & $\mathbf{4}^{\text {th }}$ & $\mathbf{5}^{\text {th }}$ \\
\hline Season 1 & WINTER & 0.0010 & 0.0004 & 0.0002 & 0.0002 & 0.0001 \\
Season 2 & SUMMER & 0.2800 & 0.2500 & 0.1000 & 0.0900 & 0.0400 \\
Season 3 & SPRING & 0.5100 & 0.4700 & 0.3400 & 0.3100 & 0.2000 \\
Season 4 & AUTUMN & 0.1700 & 0.1500 & 0.0900 & 0.0800 & 0.0500 \\
Fatigue total & & 0.9600 & 0.8700 & 0.5300 & 0.4800 & 0.2900 \\
Damage Dj & & & & & & \\
\hline
\end{tabular}


Table 5: Computation of rutting accumulated damage for all seasons

\begin{tabular}{|c|c|c|c|c|c|c|}
\hline Season & & $1^{\text {st }}$ & $2^{\text {nd }}$ & $3^{\text {rd }}$ & $4^{\text {th }}$ & $5^{\text {th }}$ \\
\hline Season 1 & WINTER & 0.00002 & 0.0000007 & 0.0000003 & 0.0000001 & 0.00000006 \\
\hline Season 2 & SUMMER & 0.00400 & 0.0010000 & 0.0005000 & 0.0002000 & 0.00010000 \\
\hline Season 3 & SPRING & 0.00200 & 0.0005000 & 0.0003000 & 0.0001000 & 0.00006000 \\
\hline Season 4 & AUTUMN & 0.00080 & 0.0002000 & 0.0000900 & 0.0000500 & 0.00002000 \\
\hline Rutting & & 0.00700 & 0.0020000 & 0.0010000 & 0.0000000 & 0.00000000 \\
\hline \multicolumn{7}{|l|}{ Total } \\
\hline Damage I & & & & & & \\
\hline
\end{tabular}

From Table 4.0 and 5.0 it is deduced that:-

i. The lowest level of damage with respect to both fatigue and rutting failure is recorded during season-1' Winter, 'this is because of the effect of low temperature on the pavement modulus of elasticity, that makes it very stiff.

ii. The highest level of damage with respect to rutting is recorded during season-2
'Summer,' which is as a result of the effect of moisture on the pavement subgrade material resilient modulus that makes it very weak.

iii. The highest level of damage with respect to fatigue is recorded during season-3 'Spring,' which is as a result of the effect of high temperature on the pavement surface modulus of elasticity which makes it weak.

Table 6: Overall System reliability index and probability of failure between the two failure modes (fatigue and rutting), $\mathrm{COV}=25 \%$

\begin{tabular}{|c|c|c|c|c|c|}
\hline & $\mathbf{1}^{\text {st }}$ & $2^{\text {nd }}$ & $3^{\text {rd }}$ & $4^{\text {th }}$ & $5^{\text {th }}$ \\
\hline $\begin{array}{l}\boldsymbol{\beta}_{1}(\mathbf{n}, \boldsymbol{\& N R} \text {, are Normal Distribution }) \\
\text { Reliability } \\
\text { Index }\end{array}$ & 1.8400 & 2.0400 & 2.7800 & 2.9600 & 3.7700 \\
\hline Probability Of Failure $\left(\mathbf{P}_{\mathbf{F}}\right)$ & 0.4500 & 0.2800 & 0.1400 & 0.0800 & 0.0500 \\
\hline $\begin{array}{l}\beta_{2}(\mathbf{n}, \& N R, \text { are Log-Normal } \\
\text { Distribution) } \\
\text { Reliability } \\
\text { Index }\end{array}$ & 2.0200 & 2.2300 & 3.0700 & 3.2300 & 4.1500 \\
\hline Probability Of Failure $\left(\mathbf{P}_{\mathrm{F}}\right)$ & 0.2900 & 0.1700 & 0.0600 & 0.1100 & 0.0100 \\
\hline $\begin{array}{l}\beta_{3}(\mathbf{n}, \boldsymbol{\& N R}, \text { are Gumbel } \\
\text { Distribution }) \\
\text { Reliability } \\
\text { Index }\end{array}$ & 2.3400 & 2.5900 & 3.5300 & 3.7600 & 4.8000 \\
\hline Probability Of Failure $\left(\mathbf{P}_{F}\right)$ & 0.4800 & 0.2400 & 0.0400 & 0.0600 & $7.200 \times 10^{\wedge}-3$ \\
\hline
\end{tabular}

Table- 6 shows the overall system reliability index value $(\beta)$ and the corresponding probability of failure $\left(\mathrm{P}_{\mathrm{f}}\right)$ produced using 3-different probability distributions (Normal, Log-Normal, and Gumbel). It should however be pointed out that system reliability for the entire pavement system when fatigue and rutting are considered as two different failure modes, is low compared to individual component reliability index, this implies that section of the road may have high reliability index with respect to fatigue but failed woefully in the reliability index with respect to rutting and vice versa, therefore reliability based design of flexible pavement should always be based on system reliability between the two failure mode(fatigue and rutting) and not component, this corresponds to the finding in [17]. Similarly, it is found that as the reliability index value increases, the probability of failure decreases, which tallies with the reality of the situations. Gumbel distribution produced highest values of reliability index, followed by Log-Normal, while Normal distribution produced lowest value. This showed that Gumbel distribution is more sensitive to the distress model equations than others.

\subsection{CONCLUSION AND RECOMMENDATION 4.1 Conclusions \\ The following conclusions were drawn: \\ i. Season-I (Winter) has recorded the highest component reliability index with respect to fatigue and the lowest level of damage with respect to both fatigue and rutting failure. By implication the season has favorable effect on flexible pavement (roads have longer design}


life during this season), and this is because of the effect of low temperature on the pavement resilient modulus during the season period that makes it very stiff.

ii. Season-II (Summer)has recorded the lowest component reliability index and highest level of damage with respect to Rutting. By implication flexible pavement roads are being adversely affected by rutting stresses during this season, which is as a result of the effect of moisture on the pavement subgrade material resilient modulus that makes it very weak.

iii. Season-III (Spring) has recorded the lowest component reliability index $(\beta)$ and the highest level of damage with respect to fatigue. By implication flexible pavement roads are being adversely affected by fatigue stresses during this season, which is as a result of the effect of high temperature on the pavement surface resilient modulus which makes it weak.

iv. The effect of choice of probability distribution of random variables was also reflected in the results for both component and system reliability index computation, where Gumbel produced highest reliability index, followed by Log-Normal, while Normal produced lowest reliability index.

\subsection{Recommendation}

Based on the results obtained in the study, the following recommendations are made:

Reliability based empirical mechanistic pavement analysis approach should be adopted for designing of all our flexible pavement in Nigeria, in order to save our roads from all the drawbacks stated for deterministic approach.

The Mechanistic empirical reliability-based design of flexible pavement should be based on system reliability between the two-failure mode (Fatigue and Rutting) that comprises all the seasons within the year and not component reliability.

The Log-Normal distribution should be used as probability distribution for both the applied and allowable ESALS application for being considered as Load variables and not Resistance.

\section{REFERENCES}

[1] AASHTO." Guide for Design of Pavement Structures, American Association of State Highway and Transportation Officials" (1993)

[2] Rutherford, J. Q, "Management of Uncertainty for Flexible Pavement Design Utilizing Analytic and Probabilistic methods". Phd Dissertation, Vanderbilt University, (2012)
[3] Timm, D.H., Newcomb, D.E. and Birgisson, B. "Incorporation of Reliability into the Minnesota Mechanistic-Empirical Pavement Design Method" Final Report, University of Minnesota, Department of Civil Engineering, (1999).

[4] Thompson, M. R., and Nauman, D. "Rutting Rate Analyses of the AASHO Road Test Flexible Pavements: In Transportation Research Record 1384, TRB", National Research Council, Washington, D.C. (1993), 36-48.

[5] Deepthi. D, Pravin. R, and Sivakumar, B. "System Reliability Analysis of Flexible Pavement Journal of Transportation Engineering,139(10), (2013), 1001-1009.

[6] Luo, Z., Xiao, F., and Sharma, R. (2014). Efficient reliability-based approach for mechanistic-empirical asphalt pavementdesign. Construction and Building Materials ,64,157165. doi.:10.1016/j.conbuildmat.2014.04.071.

[7] Dinegdae, Y. H. Reliability-based Design Procedure for Flexible Pavements, (n.d. 2015).

[8] Rackwitz, R. "Reliability Analysis, Past, Present and Future". $8^{\text {th }} A S C E$ Specialty Conference on Probabilistic Mechanics and Structural Reliability, (2000).

[9] Aashis, K. "Development of Simplified Framework for Reliability Analysis of Flexible Pavement Using Mechanistic Empirical Pavement" (2017).

[10] Claros, G., Carmichael, R. F., and Harvey, J. "Development of Pavement Evaluation Unit and Rehabilitation Design Procedure for Overlay Design Method, Vol. 2. Overlay Design Manual", Texas Research and Development Foundation for the Nigeria Federal Ministry of Works and Housing, Lagos, August 1986.

[11] Murana, A.A and Olowosulu, A.T., "Evaluation of Fatigue Models for Empirical-Mechanistic Design of flexible Pavement". World Journal of Engineering and Pure and Applied Science, 2(2), (2012a), 74-80.

[12] Murana, A.A and Olowosulu, A.T., "Evaluation of Rutting Models Using Reliability for Empirical- Mechanistic Design of Flexible Pavement". Journal of Engineering and Applied Sciences, 7(2), (2012b), 123-127.

[13] Ameri, M., Khavandi, A. "Development of mechanistic-empirical flexible pavement design in Iran".

Journal of Applied Sciences, 9(2), (2009), (354359). https://doi.org/10.3923/jas.2009.354.359.

[14] Murana, A. A. "Reliability based pavement performance model", Unpublished M.sc Thesis, Ahmadu Bello University, Zaria, September, (2010). 
[15] National Bureau of Statistics' www.nigerianstat.gov.ng, Accessed on May 23, 2021.

[16] Yakubu, M. "Climatic effects in Mechanistic Empirical pavement Design", Unpublished Msc Thesis,
Ahmadu Bello University, Zaria, (2011).

[17] Indrajit, G. Reliability analysis of Flexible Pavements using Mechanistic Empirical Approach, (2005). 